Germanistische Arbeitshefte $\quad 15$

Herausgegeben von Otmar Werner und Franz Hundsnurscher 

Ulrich Ammon

\section{Probleme der}

Soziolinguistik

2., durchgesehene und ergänzte Auflage

Max Niemeyer Verlag

Tübingen 1977 
1. Auflage 1973

CIP-Kurztitelaufnahme der Deutschen Bibliothek

Ammon, Ulrich

Probleme der Soziolinguistik. - 2., durchges. u. erg. Aufl. - Tübingen: Niemeyer, 1977.

(Germanistische Arbeitshefte ; 15)

ISBN 3-484-25017-8

ISBN 3-484-25017-8

(C) Max Niemeyer Verlag Tübingen 1977

Alle Rechte vorbehalten. Ohne ausdrückliche Genehmigung des Verlages ist es auch nicht gestattet, dieses Buch oder Teile daraus auf photomechanischem Wege zu vervielfältigen. Printed in Germany 